\title{
Sistem Pengamanan Perlintasan Kereta Api Terhadap Jalur Lalu Lintas Jalan Raya
}

\author{
Oyi adi sutrisno, Faisal Irsan Pasaribu, Indra Roza \\ Program Studi Teknik Elektro, Fakultas Teknik \\ Universitas Muhammadiyah Sumatera Utara (UMSU) \\ Jl. Kapten Muchtar Basri,BA No. 03 Medan Telp. (061) 6622400 ex. 12 Kode pos 20238 \\ e-mail: oyiadisutrisno@gmail.co.id
}

\begin{abstract}
Abstrak - Saat ini banyak pengerdara sepeda motor maupun pengendara roda 4 (mobil) yang menerobos lampu lalu lintas (trafic light) dan melanggar rambu lalu lintas karna itu dapat membahayakan pada pengemudi kendaraan.kurangnya kesadaran diri untuk keselamatan saat berada dipertlintasan kereta api yang berpalang ,maka timbulah ide untuk merancangan sistem pengamanan lalu lintas yang diharapkan bisa mengatasi tidak dislipinnya pengemudi kendaraan.
\end{abstract}

Kata kunci : LCD, arduino,motor servo,lampu led,switch limit

\begin{abstract}
Currently many motorbike drivers and 4-wheelers (cars) break through traffic lights and violate traffic signs because it can be dangerous for vehicle drivers. Lack of self-awareness for safety while on a railroad crossing that is barred, then arises idea to design a traffic security system that is expected to be able to overcome the dislocation of vehicle drivers.
\end{abstract}

Keywords : $\quad$ LCD, Arduino, servo motor, LED lights, switch limit

\section{PENDAHULUAN}

Kereta api merupakan angkutan massal yang memiliki banyak kelebihan dari moda angkutan lain terutama sebagai solusi dari masalah kemacetan yang terjadi di tanah air. Kenyamanan dalam perjalanan yang bebas macet membuat banyak masyarakat menggunakan moda transportasi ini sebagai alat transportasi mereka. Tingginya minat masyarakat pada kereta api ditanggapi positif oleh pemerintah karena sesuai dengan semangat pemerintah untuk mengadakan moda transportasi massal yang dapat mengurangi kemacetan, hemat energi dan lebih ramah lingkungan sehingga pembangunan dan perbaikan prasarana serta sarana kereta api semakin ditingkatkan pula. Semakin meningkatnya jumlah sarana kereta api membuat lalu lintas perjalanan kereta api juga menjadi semakin padat sementara peningkatan jumlah jalur cenderung tetap sehingga sering membuat kereta api harus saling menunggu giliran memakai jalur sesuai dengan perintah yang diberikan petugas pengatur perjalanan kereta api dari stasiun karena beberapa kereta api itu akan melewati jalur yang sama.

Dengan prosedur perjalanan seperti ini seharusnya keamanan perjalanan kereta api dapat dijaga sebab selama petugas pengatur perjalanan kereta api distasiun mampu memonitor keberadaan kereta api dan dapat mengaturnya dengan memberi arahan yang jelas melalui sistem persinyalan yang ada serta masinis yang berada diatas kereta api tetap konsentrasi dalam melihat sinyal yang diberikan ketika menjalankan kereta api maka semua perjalanan kereta api akan aman. Namun beberapa tahun belakangan ini ada terjadi tabrakan antar kereta api distasiun yang menimbulkan banyak korban jiwa. Hal ini membuktikan bahwa untuk menjaga keamanan perjalanan kereta api tidaklah cukup hanya dengan kemampuan manusia saja, namun juga perlu didukung oleh teknologi. Pada saat ini teknologi yang banyak dipakai oleh negara-negara maju dalam memonitor perjalanan kereta api mereka adalah GPS.

Dengan menggunakan GPS posisi dan kecepatan kereta api dapat dipantau oleh petugas sehingga petugas dapat lebih menjaga keselamatan perjalanan kereta api. GPS (Global Positioning System) adalah sistem satelit navigasi dan penentuan posisi yang dimiliki dan dikelola oleh Amerika Serikat.Sistem ini didesain untuk memberikan posisi dan kecepatan tiga-dimensi serta informasi mengenai waktu, secara kontinyu di seluruh dunia tanpa bergantung waktu dan cuaca, bagi banyak orang secara simultan. Saat ini GPS sudah banyak digunakan orang di seluruh dunia dalam berbagai bidang aplikasi yang menuntut informasi tentang posisi, kecepatan, percepatan ataupun waktu yang teliti.GPS dapat memberikan informasi posisi dengan ketelitian bervariasi dari beberapa millimeter (orde nol) sampai dengan puluhan meter. Di Indonesia sendiri penggunaan GPS sudah dimulai sejak beberapa tahun yang lalu dan terus berkembang sampai saat ini baik dalam volume maupun jenis aplikasinya.(Yudi Yuliyunus M.)

Perlintasan kereta api yang ada di Indonesia masih banyak yang belum memiliki fasilitas yang memadai contohnya alat pemantau keamanan perlintasan kereta api sehingga petugas pos yang bekerja mengalami 
kesulitan dalam memantau keamanan di area perlintasan kereta api. Selain itu, sistem membuka dan menutup pintu perlintasan masih dilakukan secara manual. Hal ini membuat sistem keamanan di perlintasan menjadi kurang efisien. Untuk meningkatkan keamanan dan memudahkan petugas dalam mengawasi area pintu perlintasan, dibutuhkan alat bantu yang dapat memantau perlintasan kereta api menggunakan CCTV yang terkoneksi dengan handphone petugas, agar petugas dapat memantau perlintasan kereta api walaupun sedang tidak berada di tempat. Selain itu, dibuat juga palang pintu perlintasan yang dapat membuka dan menutup secara otomatis untuk mengurangi kemungkinan terjadinya kegagalan operator dalam membuka dan menutup pintu perlintasan. Oleh karena itu dibuatlah alat pemantau keamanan perlintasan kereta api yang akan memantau ketika kereta api datang. kemacetan dan kecelakaan untuk diterapkan dijalan raya. Berdasarkan uraian diatas maka peneliti akan merancang "Sistem Pengamanan Perlintasan Kereta Api Terhadap Jalur Lalu Lintas Jalan Raya”.

\section{TINJAUAN PUSTAKA}

Tinjauan Pustaka Relevan

Sering terjadinya kemacatan serta kecelakaan di persimpangan perlintasan kereta api di jl.prof HM.yamin sh, disebabkan karena padatnya volume kendaraan yang melintas dijalan tersebut.serta frekuensi kereta api yang melintas juga cukup sering mengakibatkan kepadatan kendaraan akan semakin bertambah di jam-jam sibuk seperti pagi hari dan Jam pulang kerja sore hari.kemacatan tentu ti dak terhindarkan lagi,serta perilaku pengendara yang tidak tertib berlalu lintas semakin memperparah kemacatan di wilayah tersebut.tidak jarang terjadi kemacatan akibat mereka terjebak di perlintasan kereta api.

Di samping itu pengaturan traffic light belum terasa optimal,traffic light yang ada di perlintasan kereta saat ini tidak situasional karena apabila pengaturan traffic light sudah situasional maka kemacatan yang terjadi bisa diminimasilir hamper semua perlintasan kereta api fungsi traffic light belum terintegrasi dengan kedatangan kereta api.contoh adalah ketika traffic light dijalur satu yang memotong jalur 2 berwarna hijau,sementara dijalur 2 traffic light berwarna marah.di saat bersamaan peringatan dini keberadaan kereta api berbunyi, otomatis palang pintu akan diturunkan dan praktis kendaraan dari jalur 1 akan berhenti selama kereta api melintas padahal lampu masih hijau. setelah kereta api lewat traffic light berubah menjadi merah bayangkan apabila frekuensi kereta yang lewat tinggi,maka kemacatan akan semakin parah pada jalur 1 karena durasi traffi light hijaunya akan berkurang setiap kereta api melintas.sementara pada jalur 2 meskipun traffi light merah,kendaraan masih bisa melintas, apabila disaat yang bersamaan kereta juga melintas.meski pun hal itu melanggar aturan,hal ini tentu tidak akan terjadi apabila kita bisa mengoptimalkan system penteksi kedatangan atau keberadaan kereta pada lintasan tersebut,skripri ini saya angkat dari jurnal.(Ali Murtadlo, 2009), (Anonim, 2009)

\section{Bagian Hardware}

Berupa papan yang berisi $\mathrm{I} / \mathrm{O}$, seperti

Gambar berikut

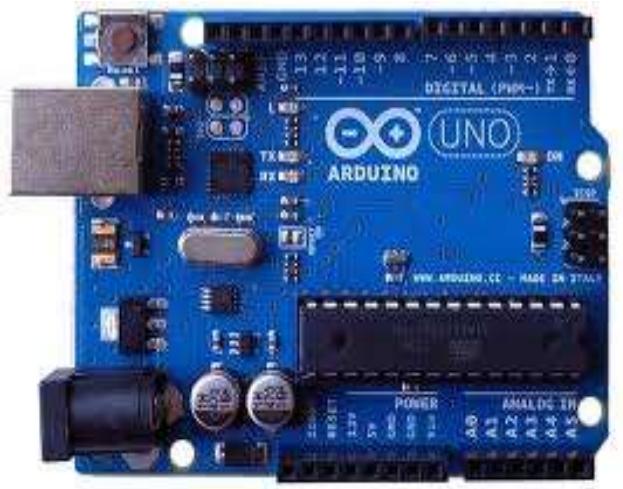

Gambar 1. Board Arduino

(Sumber: Yuwono Martha Dinata ; 2015 : 3)

Arduino memiliki 14 pin input/output yang mana 6 pin dapat digunakan sebagai output PWM (Pulse Width Modulation), 6 analog input, crystal osilator $16 \mathrm{MHz}$, koneksi USB, jack power, kepala ICSP, dan tombol reset. Arduino mampu men-support mikrokontroller; dapat dikoneksikan dengan komputer menggunakan kabel USB.

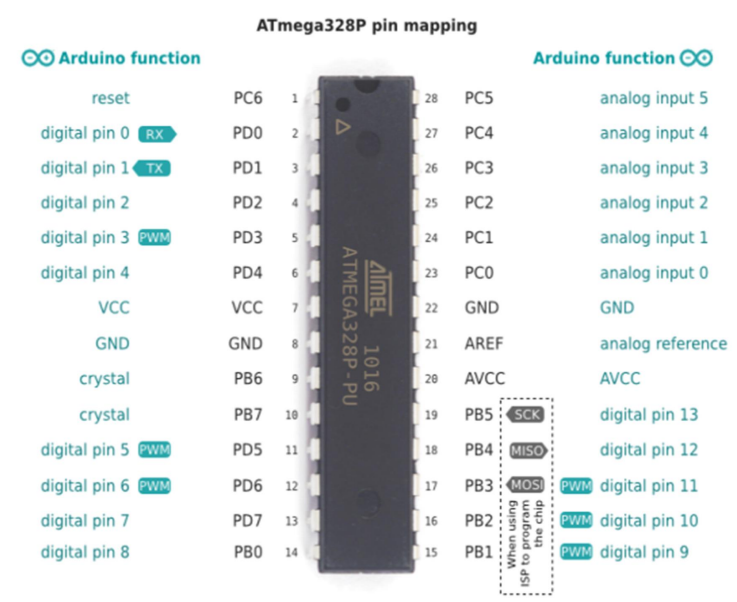

Gambar 2 Arduino Uno ATMega 328 Pin Mapping

Setiap 14 pin digital pada arduino dapat digunakan sebagai input atau output, menggunakan fungsi pinMode(), digitalWrite(), dan digitalRead(). 
Input/output dioperasikan pada 5 volt. Setiap pin dapat menghasilkan atau menerima maximum $40 \mathrm{~mA}$ dan memiliki internal pull-up resistor (disconnected oleh default) 20-50K Ohm.

Beberapa pin memiliki fungsi sebagai berikut :

1. Serial : $0(\mathrm{RX})$ dan 1 (TX). Digunakan untuk menerima (RX) dan mengirim (TX) TTL data serial. Pin ini terhubung pada pin yang koresponding dari USB ke TTL chip serial.

2. PWM : 3, 5, 6, 9, 10, dan 11. Mendukung 8-bit output PWM dengan fungsi analogWrite().

3. Interupt eksternal : 2 dan 3. Pin ini dapat dikonfigurasikan untuk trigger sebuah interap pada low value, rising atau falling edge, atau perubahan nilai.

4. SPI : 10 (SS), 11 (MOSI), 12 (MISO), 13 (SCK). Pin ini mensuport komunikasi SPI, yang mana masih mendukung hardware, yang tidak termasuk pada bahasa arduino.

5. LED : 13. Ini adalah dibuat untuk koneksi LED ke digital pin 13. Ketika pin bernilai HIGH, LED hidup, ketika pin LOW, LED mati.

2. Bagian Software

Berupa Sofware Arduino yang meliputi Integrated Depelopment Enviroment (IDE) untuk menulis program. Arduino memerlukan instlasi driver untuk menghubungkan dengan komputer. Pada IDE terdapat contoh program dan library untuk pengembangan program. IDE software Arduino yang digunakan diberi nama Sketch, seperti Gambar berikut.

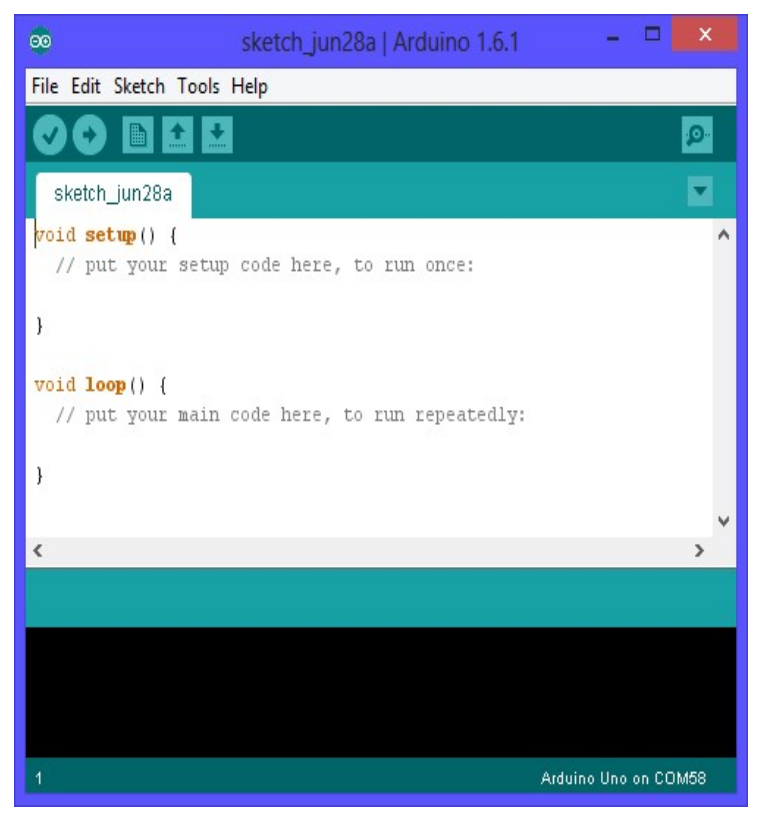

Gambar 3 Software Arduino

(Sumber: Yuwono Martha Dinata ; 2015 : 4)

\section{METODE}

\section{Lokasi Penelitian}

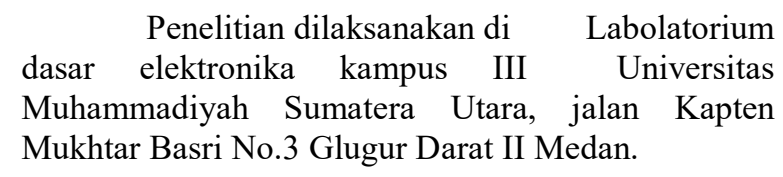

\section{Peralatan dan Bahan Penelitian}

Adapun bahan dan alat yang digunakan pada penilitian ini sebagai berikut :

\section{Bahan dan Peralatan Penelitian}

Bahan-bahan yang digunakan untuk sistem pengamanan lalu lintas dari kemacatan saat kereta api melintas ini yaitu

1. Adaptor berfungsi menghidupkan program..

2. LCD 2 x 16 digunakan untuk menampilkan data sensor.

3. Arduino Uno digunakan untuk mengontrol rangkaian keseluruhan.

4. Saklar ON/OFF berfungsi untuk menghubung dan memutuskan tegangan.

5. Timah sebagai bahan yang akan menghubungkan kaki komponen dengan jalur tembaga.

6. Kabel Jamper yang akan digunakan untuk menghubungkan jalur rangkaian yang terpisah.

7. Triplek digunakan sebagai alas tempatnya miniatur diletakkan.

\section{Peralatan Penelitian}

Peralatan penunjang yang digunakan untuk membuat Sistem Pengamanan Perlintasan Kereta Api Terhadap Jalur Lalu Lintas Jalan Raya ini yaitu:

1. Arduino Uno

Arduino merupakan mikrokontroler yang memang dirancang untuk bisa digunakan dengan mudah oleh para teknisi.Dengan demikian, tanpa mengetahui bahasa pemograman, Arduino bisa digunakan untuk menghasilkan karya yang canggih.Hal ini seperti yang diungkapkan oleh Mike Schmidt.

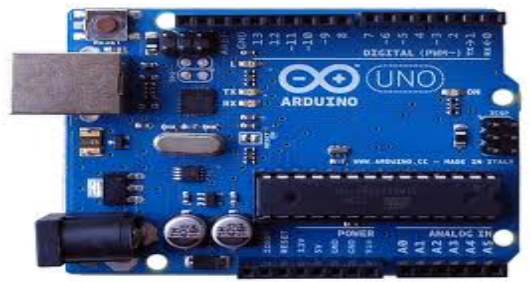

2. Motor Servo

Motor servo adalah sebuah perangkat atau aktuator putar (motor) yang dirancang dengan sistem 
kontrol umpan balik loop tertutup (servo), sehingga dapat di set-up atau di atur untuk menentukan dan memastikan posisi sudut dari poros output motor.

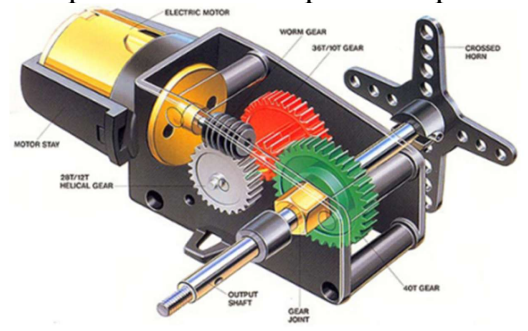

3. Multimeter sebagai pengukur dan pengetesan komponen yang mengacu pada besaran hambatan, Arus, dan Tegangan.

4. Bor digunakan untuk membuat lubang pada PCB.

5. Solder untuk mencairkan timah.

6. Solder Atraktor sebagai penyedot timah.

7. Bor kayu dengan mata ukuran diameter $3 \mathrm{~mm}$, dan $6 \mathrm{~mm}$.

8. Penggaris untuk mengukur PCB.

9. Pisau Cutter untuk memotong pelat PCB sesuai ukuran.'

10. Tang digunakan untuk memotong maupun mengelupas kabel maupun memotong kaki komponen

11. Triflek sebagai wadah simulasi rangkaian

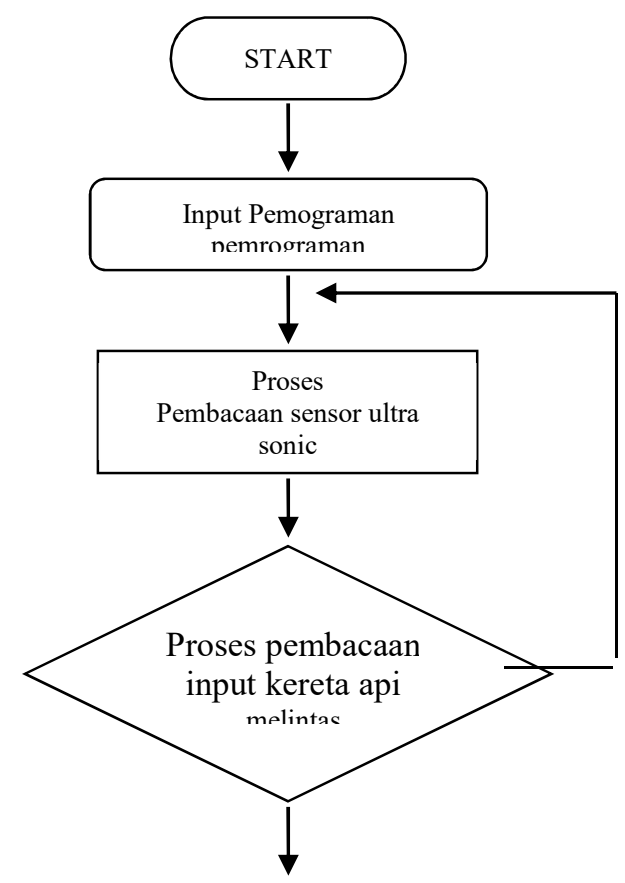

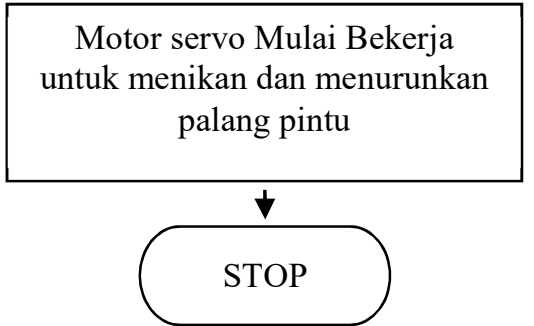

Gambar 4. Flowchart Sistem

\section{HASIL DAN PEMBAHASAN}

Hasil Penelitian

Hasil proses pengujian alat yang telah dikerjakan sangat menentukan berhasil tidak nya alat yang telah dikerjakan. Setelah pengujian dapat diketahui apakah alat yang telah dikerjakan mengalami kesalahan atau perlu diadakan perbaikan, dalam setiap pengujian dilakukan pengukuran yang nantinya akan digunakan untuk menganalisa hardware dan software serta komponen - komponen pendukung lainnya.

Rangkaian Sistem Minimum Arduino Uno R3

Modul Arduino pada penelitian ini berfungsi sebagai control dari semua sistem pada mengatur pengamanan lalu lintas dari kemacatan saat kereta api melintas. Adapun Arduino yang dipakai pada penelitian ini adalah Arduino Uno R3.

Peralatan yang dibutuhkan untuk melakukan pengujian ini yaitu :

1. Minimum Sistem Arduino Uno R3

2. Kabel data Arduino Uno R3

3. Software Arduino IDE

Blok diagram pengujian rangkaian LCD dengan Arduino Gambar berikut :

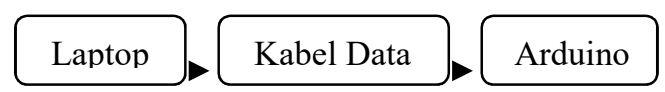

Gambar 5 Blok Diagram Pengujian Modul Arduino Uno

Pengujian Motor Servo

Secaraprinsip, semua servo memiliki kaki dan fungsi yang sama.Namun ada dua jenis servo yang umum di pasaran, adayang putarannya terbatas, ada yang berputar hingga 360 derajat namun juga 
motor servo dapat berputar hingga 180 derajat.Motor servo terdiri dari tiga buah kabel, kabel VCC(merah), GND (coklat), dan PWM (jingga). Fungsi kabel VCCdan GND sudah jelas sebagai jalur power supply. Sedangkankabel PWM untuk mengatur arah putaran servo.

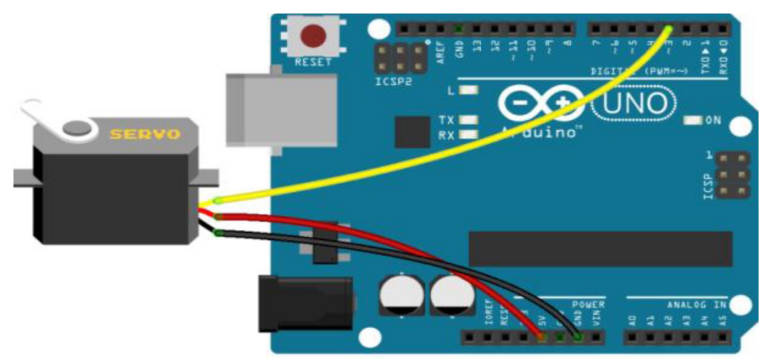

Gambar 6 Pengujian Motor Mervo

Menampilkan Pengujian Coding Program Motor servo

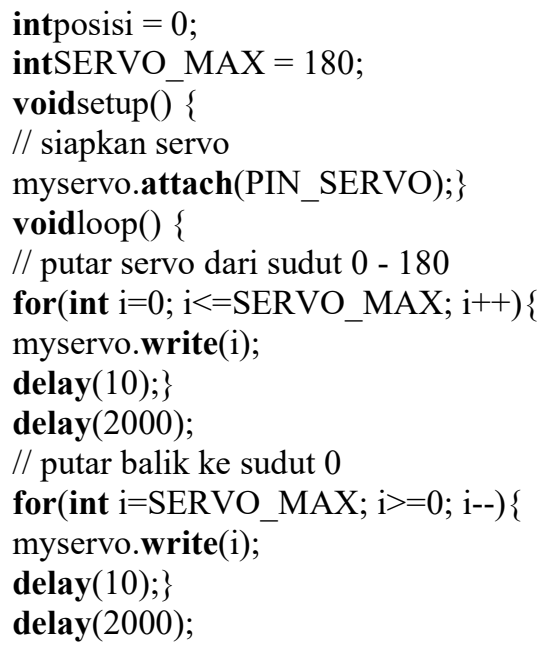

Pengujian Sensor Infraret

Rangkaian sensor infraret ketika bagian lain yang lebih elastic mendapat bayangan, maka pada sisi lain akan mengalami perubahan tegangan yang sesuain dengan yang dihasilkan oleh lewat kereta Api.

Dalam pengujian sensor infraret adalah untuk mendeteksi kereta api yg akan melintas.

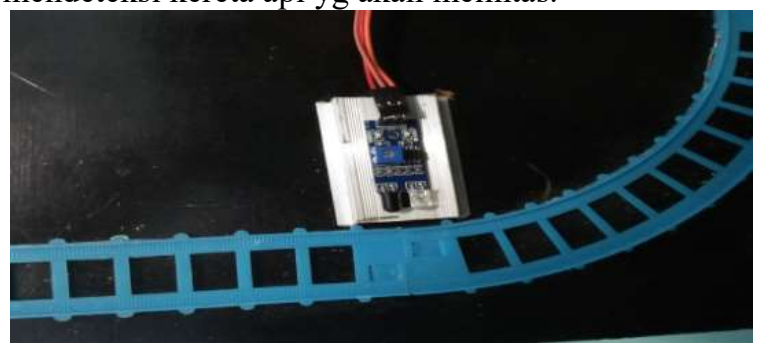

Gambar 7 Rangkaian Sensor Infraret
// variables will change:

int infraRed $=0$;

void $\operatorname{setup}()\{$

// initialize the LED pin as an output:

pinMode(ledPin, OUTPUT);

// initialize the pushbutton pin as an input:

pinMode(InfraPin, INPUT); $\}$

void $\operatorname{loop}()\{$

// read the state of the pushbutton value:

InfraState $=$ digitalRead(InfraPin);

// check if the pushbutton is pressed. If it is, the buttonState is HIGH:

if (IntraState $==\mathrm{HIGH})\{$

// turn LED on:

digitalWrite(ledPin, LOW);

\} else \{

// turn LED off:

digitalWrite(ledPin, HIGH);

\section{KESIMPULAN}

Dari perancangan alat sistem pengamanan perlintasan kereta api terhadap jalur lalu lintas jalan raya berbasis arduino, kemudian dilakukan pengujian dan analisanya sehingga menghasilkan pengujian yang telah dilakukan, bahwa apabila kereta api mlintas dengan jarak 50 meter maka seensor ultra sonik bekerja membaca program, palang kereta akan turun secara otomatis. Pada pengujian alat ketika sensor ultra sonic bekerja maka program akan bekerja untuk menaikan aspal, miniatur ini di buat untuk mengurangi angka kecelakaan saat kereta api melintas. Pada penerapan alat ini, alat perancangan pengamanan perlintasan kereta api terhadap jalur lalu lintas jalan raya berbasis arduino dapat diterapkan oleh PT. KAI, karna alat ini sangat sederhana dan bisa terapkan oleh PT. KAI.

Untuk pengembangan lebih lanjut dari alat ini agar lebih sempurna, maka beberapa saran berupa Pengembangan alat ini sangat masih sangat memungkinkan dan dapat disempurnakan dengan adanya penambahan-penambahan sensor dan wifi agar bisa memantau dari jarak jauh. Perlunya ditambahkan pengamanan disetiap kereta api melintas agar masyarakat lebih berhati-hati dalam melewati lintasan kereta api dan mengurangi angka kecelakaan. Sistem palang dan aspal yang naik saat kereta api melintas, disitu bisa ditambahkan lagi dengan sensor yang lebih akurat.

\section{DAFTAR PUSTAKA}

[1] Abdul Kadir , "Scratch for Arduino(S4A)", Penerbit Andi, Yogyakarta, 2015.

[2] Abdul Kadir, "Panduan Praktis Mempelajari Aplikasi Mikrokontrole dan Pemeogramannya menggunakan Arduino", Penerbit Andi, Yogyaka rta, 2013. 
[3] Abdul Kadir, "From Zero to a Pro",Penerbit Andi, Yogyakarta, 2014.

[4] Abdul Kadir , "Simulasi Arduino", Penerbit Andi, Yogyakarta, 2016.

[5] Ali murtdlo (2009): Simulasi system informasi posisi kereta api dengan menggunakan GPS untuk keselamatan penumpang,intitut teknologi sepuluh nopember Surabaya
[6] FI Pasaribu, S Yogen, Perancangan Prototype Troli Pengangkut Barang Otomatis Mengikuti Pergerakan Manusia, RELE (Rekayasa Elektrikal dan Energi): Jurnal Teknik Elektro 1 (2), 8292, 2019 